\title{
26 MANAGING KNOWLEDGE DEVELOPMENT IN THE NETWORK ECONOMY: METHODOLOGICAL CONTRIBUTIONS
}

\author{
Håkan Sterner \\ School of Management and Economics \\ Växjö University \\ $S E-35195$ Växjö \\ Sweden
}

\begin{abstract}
The business conditions associated with the network economy have implied difficult challenges related to organizational and inter-organizational knowledge development. This paper delineates problem areas in this context and outlines a model of knowledge development intended to serve as a methodological contribution to knowledge management. The model is defined in relation to a conceptual framework that compiles elements from evolutionary epistemology, the concept of tacit knowing, theories of systemic thinking, and decision making. The usefulness of the result is discussed in relation to the described problem areas.
\end{abstract}

\section{INTRODUCTION}

In one of the most comprehensive analyses of the information age to date, Manuel Castells (1996) identifies two trends as fundamental for understanding the network economy. One is informationalization, referring to the productivity and competitiveness of agents (e.g., organizations, regions, and nations) as being increasingly determined by their ability to generate, process, and effectively apply knowledge-based information. The other trend is globalization, denoting the organization of core activities, components, and resources on a global scale, 
either directly or through a network of connections between economic agents. Both are seen as having been propelled by the rapid development of information technology during the last quarter of the $20^{\text {th }}$ century.

This paper aims to promote methodological development within the field of knowledge management $(\mathrm{KM})$ in directions that are consistent with business conditions of the network economy. Here we will focus on the issue of frameworks and models for conceptualizing the problem area since these elements are central in problem-solving methodologies: they act as "cognitive filters" that emphasize particular perspectives of "reality" to the problem solver, and serve as a rational basis for choosing a course of action (Jayaratna 1994). To this end, a model of knowledge development in organizational and inter-organizational contexts is proposed as the theoretical foundation for $\mathrm{KM}$ methodologies $(\mathrm{KMM})$. Here, $\mathrm{KMM}$ is tentatively defined as intervention approaches to improve the client's capability to manage knowledge and learning. The model is defined within a conceptual framework that compiles elements from a body of theory including evolutionary epistemology, the concept of tacit knowing, and theories of systemic thinking and decision making. The result is discussed in relation to the problematic conditions of the network economy that are elaborated in the next section.

\section{MANAGEMENT OF KNOWLEDGE DEVELOPMENT IN THE NETWORK ECONOMY}

Two distinct phenomena related to the network economy can be emphasized to develop a characterization of issues that need to be addressed by future KMMs. First, it is observed that the most important sources of knowledge tend to be external to the economic agents, implying that the raw material for competitive advantage cannot be brought under the control of companies and nations and exploited as production resources in the usual sense. This necessitates new and more flexible strategies of ensuring viability and long-term survival in the post-industrial business environment. Empirical studies indicate that development of technology, productivity, and business operations in many enterprises is highly dependent on their base of customers and suppliers. The key to success lies in the ability to mobilize and utilize their resources, activities, and individuals through complex and unique business relations that take a long time to develop (Lundgren and Snehota 1998). A similar strategy has been observed on a global scale, where traditional strategies of investing abroad to gain control are being replaced by strategies to get access to markets through complex networks of relations between companies in different institutional environments (Castells 1996, Chapter 3). The precondition for competitive use of knowledge is to have access to timely information from agents in close contact with the external 
sources. Problematic issues in this context concern the maintenance and development of the increasingly complex network of contacts that gives the agent access to critical resources.

The second phenomenon is the increasing use of articulated or codified information (e.g., manuals, documented working procedures, and customer records) in the dissemination and exchange of knowledge, which appear to have been the most common objective in knowledge management projects (Davenport et al. 1998). Its popularity can be seen as being produced by several factors. First, the availability of increasingly more efficient information technology for capturing information, to store it in databases, and to give opportunities of searching and retrieving needed "pieces of knowledge" on a large scale. A second factor is found in an organizational interest of attempting to restore the balance of power between the autonomous workers and the knowledge base of the firm (Swan et al. 1999), given knowledge as the critical production resource. Another contributing factor is, of course, the increasing needs to transcend barriers of time and distance in communication due to the globalization of business activities. Here we would like to draw attention to the problems that tend to arise in knowledge exchange situations when involved parties have different experiential and/or educational backgrounds. Schein (1996) discuss this problem at an intra-organizational level, and identifies three "occupational cultures" in organizations: an operator, an engineering, and a management culture. These cultures are associated with very different sets of assumptions and values, and his point is that organizational learning will be severely impaired as long as organizations fail to confront the implications of the three occupational cultures. If cultural barriers are a recognized problem at the level of an organization, they are hardly less of a problem on the interorganizational and global arena of the network economy.

\section{THE KMM FRAMEWORK}

The concepts and constructs of the KMM framework to be presented below have been selected as a result of a literature study within the fields of systems thinking, decision making, and organizational learning (Sterner 2000).

\subsection{Evolutionary Development}

Heylighen (1992) stresses the importance of an evolutionary outlook in general systems studies and elaborates on the fundamental principles regarding how systems develop in relation to environmental constraints. In this case, we have the evolution of personal knowledge in mind. First, there is the basic Darwinist principle of blind variation and selective retention (BVSR), which 
states the variation processes are not required to know which of the variants they produce are more likely to be selected than others. This is widely accepted in the generation of variety by means of genetic recombination and mutation, but is also a recognized theory for domains such as human problem solving and the development of expert skills, as will be explained in section 3.2.

The second is the principle of selective variety, which states that the larger the variety of configurations a system is capable of producing, the larger the probability that at least one of these configurations will be selectively retained, i.e., "survives." This principle is especially relevant in rapidly changing environmental conditions when coping with unknown threats: without a large initial variety, there is less of a chance that a stable configuration can be reached in time. The view that organizational memories emerge from evolutionary processes rather than from conscious design has been proposed (Nonaka and Takeuchi 1995; Weick 1979). It is argued that organizations need a large variety of information, competencies, and knowledge, and that it is difficult to assess which will be needed or prove to be valuable in future business directions. If "unnecessary" parts of the organization and its memory are done away with, as suggested by intervention approaches like business process reengineering, there is a risk that the organization will be robbed of conditions promoting innovation, thereby threatening long-term survival.

Third, the principle of recursive systems construction is put forward as an explanation of the emergence of new systems at a meta level, which is a way of describing a growing enterprise. It states that BVSR processes recursively construct stable systems by the recombination of lower-level stable elements. The relations of a system to elements of its environment initially undergo variation, of which any change can be viewed as a recombination of such relations. Some of these patterns will prove to be more stable, hence are selectively retained and form a system on a higher level. This principle seems to be at work in Maxfield's (1997) case of a successful large high-tech organization. The organization started when a small team of specialists formed a consultancy firm, providing services related to their field of technical expertise to a small number of clients. Nobody knew from start where the opportunities were or the purpose of the firm. They developed and expanded through close contacts with customers at all times.

\subsection{The Knowledge Dimension}

The fundamental dimension of knowledge that Polanyi (1958) calls "tacit knowing" is associated with evolutionary philosophy. This is knowledge developed by individuals in close contact with a specific task environment, typified by the apprentice that attempts to acquire the skills of the master by close observation, imitation, and practice (however, it should be noted that we can 
dispose of the master and still acquire expert skills, although normally at an unacceptably slow pace). To Polanyi, all knowledge is rooted in the tacit dimension. Tacit knowing has an implicit relation to objects of "focal awareness" and is characterized by being generated by processes of trial-and-error while being focally aware of its object. An individual can only have a subsidiary awareness of the tacit knowing that assists in the act of performing a task, and is unable to articulate more than a small fraction of it. Tacit knowing can be conceptualized as having cognitive and technical elements (Nonaka and Takeuchi 1995). Here, cognitive components are mental models and schemes that individuals use to make sense of their reality, while technical components concern skills and abilities that are used for influencing environmental objects (cf. Polanyi's objects of focal awareness). We would like to add a judgmental component to these two, representing morality or ethical knowing. Thus, what an apprentice may hope to learn from the master by "guided trial and error" can be usefully separated into three categories: the master's way of doing things, the master's way of understanding the world, and the master's moral judgement.

The point is that the inescapable tacit dimension in all expressions of knowledge implies that articulated knowledge only can be understood within a community of people submitting to a certain tradition that provides the needed (tacit) background knowledge and assumptions that are taken for granted. This is an important consideration in organizational knowledge management since the meaning of codes or "articulated knowledge" becomes relative to contexts of production and use. Within the KMM framework, the concept of "codified knowledge" denotes articulated knowledge that is possible to test and make use of within a given community. It has the function of evoking reasonably effective learning behavior, rather than "transferring knowledge."

\subsection{The Management Dimension}

The traditional theories about management of organizations largely use the language of power and control to think about what is expected from managers, leading to guidelines about what characterizes good management such as Colonel Mayo's principles of "span of control," "unity of command," etc. Vickers (1965) characterizes this view of management as a matter of regulation, i.e., the boss is likened with a thermostat striving to achieve some predefined norm by stereotypic behavior.

Vickers did not recognize this control model of management as something he could relate to based on his experience of public administration, management, and private life. Instead, he perceived it as an appreciative process of continually establishing and building relationships, maintaining the desired ones while eluding the undesired. It is a process in which (events and phenomena in) reality is perceived and framed according to existing norms, action is devised and 
initiated, and where the results of action continually are challenging and changing the norms. The concept of "policy making" was chosen to describe the distinctive character of this governing activity. This model seems compatible with characteristics of successful general managers (Kotter 1982): they typically excel in developing effective networks spanning organizational functions and boundaries, maintaining useful contacts by dialogue and the exchange of favors when courses of events need to be influenced at particular places in the network.

Another line of thinking about management recognizes leadership as a distinct and important phenomenon. Smircich and Morgan (1982) propose that leadership can be usefully understood as "the management of meaning." They focus the function of leading as enacting a particular view of the social reality, a form of mind control that effectively restricts the range of possible behaviors among the led. Leadership according to this view is a socially constructed phenomenon emerging through the actions and interactions of both the leaders and the led. In group contexts, e.g., a meeting, it may emerge out of struggles between people holding competing perspectives or world-views in their attempts to understand what is happening in reality. Successful attempts define a basis for joint commitments to specific strategies and actions.

\subsection{The Ontological Dimension}

This dimension of the KMM framework represents structures in the body of organizational knowing regarding what there is to know something about. One way of approaching the subject is to divide knowing into domains of knowledge, for instance, concerning stakeholders, competitors, customers, suppliers, markets, products, and operations. Here it is worth noting indications that most companies perceive the largest benefit of KM projects to be improved customer knowledge (Skyrme and Amidon 1997).

\section{A MODEL OF KNOWLEDGE DEVELOPMENT}

Building on the conceptual framework of the previous section, it is suggested that organizational knowledge development can be modeled as three interconnected processes: decision making, sense making, and policy making. Within each of these processes, there is a constant interaction between knowing at a tacit level and associated categories of codified knowledge (Figure 1). Links between the processes are conceptualized as follows. Judgements (e.g., as represented by policy statements) works as a selecting mechanism with respect to sense-making processes, which thereby limit the variety of ways of interpreting the "world" within a group. Likewise, consensual understanding (e.g., as represented by metaphors in use) works as a selecting mechanism in decision-making processes, thus having influence on the goals that are to be pursued. 


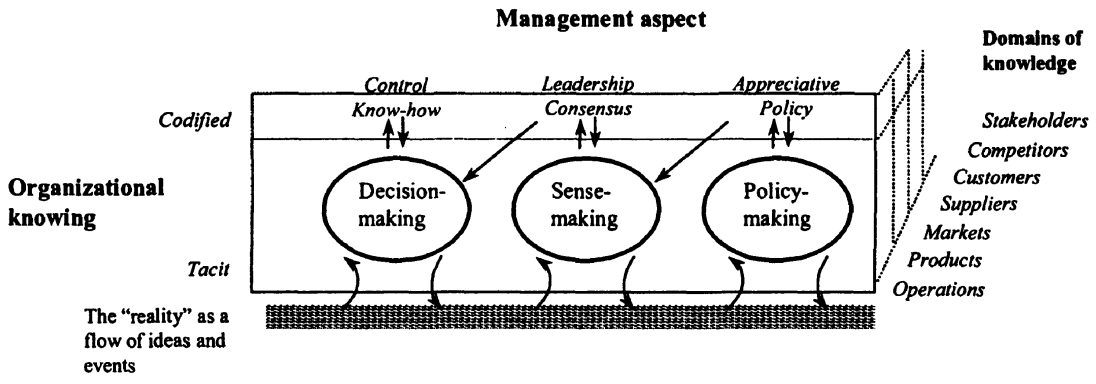

Knowing Process

\begin{tabular}{|c|c|c|c|}
\hline \multirow[b]{2}{*}{ Characteristics } & \\
\hline & Decision-making & Sense-making & Policy-making \\
\hline General characteristics & Purposeful & Reflective & Judgmental \\
\hline Social order & $\begin{array}{l}\text { Managerial, submission } \\
\text { to authority relationships }\end{array}$ & $\begin{array}{l}\text { Peer group sharing } \\
\text { practical experiences }\end{array}$ & $\begin{array}{l}\text { Informal network of } \\
\text { contacts, spanning } \\
\text { organization boundary }\end{array}$ \\
\hline $\begin{array}{l}\text { Artefacts/media of } \\
\text { knowing (codified } \\
\text { knowledge) }\end{array}$ & $\begin{array}{l}\text { Prototypes, procedures, } \\
\text { routines }\end{array}$ & $\begin{array}{l}\text { Images, concepts, } \\
\text { metaphors, language }\end{array}$ & $\begin{array}{l}\text { General guidelines, } \\
\text { statements of attitude, } \\
\text { policy, and culture }\end{array}$ \\
\hline Main metaphor & $\begin{array}{l}\text { Organizations as rational } \\
\text { entities }\end{array}$ & $\begin{array}{l}\text { Organizations as cultures } \\
\text { and sub-cultures }\end{array}$ & $\begin{array}{l}\text { Organizations as } \\
\text { political arenas }\end{array}$ \\
\hline Selecting mechanism & $\begin{array}{l}\text { Consensual schemas, } \\
\text { images, etc. Goal } \\
\text { compliance. }\end{array}$ & Policy compliance. & $\begin{array}{l}\text { Value judgments, } \\
\text { morality. }\end{array}$ \\
\hline
\end{tabular}

Figure 1. A Model of Knowledge Development Through Processes of Making Decisions, Sense, and Policy.

Intended and unintended outcomes of decision-making processes contribute to the flow of events constituting reality that is to be made sense of within the group. This may trigger new ways of understanding what is going on, adding to the flow of events and ideas that is considered in policy-making processes. Figure 1 attempts to depict the dynamic interrelations between the three processes, and give a very brief summarization of their main characteristics. It should be noted that according to Vickers' thinking, there is no ultimate source of judgement; the norms emanate from within the network itself (cf. autopoietic theory, Maturana and Varela 1980). It can also be observed that policy-making networks span traditional boundaries of organizations, thereby providing a moral alignment among its members and the organizational bodies to which they belong. 


\section{CONCLUDING DISCUSSION}

To begin with the second problem area discussed in section 2 , the present work can contribute to Schein's analysis of the three occupational cultures and the communication barriers between them by pointing out more potential barriers to take into consideration. In particular, communication barriers may be seen between the three processes of making decisions, sense, and policy, and between different domains of knowledge. Here, the barrier between operators and managers appears to occur along the process dimension, while the barrier between the engineering culture and the other two seems to be located somewhere between different knowledge domains and being more or less pronounced depending on how close they are to each other.

According to the viewpoint of evolutionary epistemology adopted here, policy statements, images, and metaphors cannot convey the meaning of what they represent by themselves. They can only be regarded as support in processes of social mediation of knowing, the usefulness being determined by its capacity to promote effective learning behavior among its participants. Consequently, if policy is to have the intended influence on sense-making activities of a team, the team leader needs to take part in the network of people developing the policy. The same principle holds for decision-making processes, where decision-makers need to take part in relevant team sense-making activities in order to understand how to frame decision situations. This means that sufficient time and opportunities must be offered for team reflection to make sense of anomalies in operational activity, and for them to design effective solution strategies that are consistent with joint policy decisions. If no acceptable solutions can be found, policy may need to be renegotiated.

The reading of the model so far should appear to be consistent, in many of its elements, with popular models, guidelines, and concepts that are seen as established theory within areas like knowledge creation, organizational learning, and organizational design-Nonaka and Takeuchi's (1995) theory of organizational knowledge creation, action learning, and circular organizational design to name a few. This is no coincidence, since the present work started out as an attempt to systematize findings from systems thinking, decision making and organizational learning into contributions to the field of KM (Sterner 2000). Regarding the relevance of the present result to the first problem area delineated in section 2-which perhaps could have been labeled "network management for business innovation at the interorganizational level"- the explicit references to evolutionary principles in the characterization of sense-making and policymaking processes blend very well with empirical accounts of how network organizations grow and develop over time. An interesting phenomenon to study would be the explanatory value of the principle of recursive systems construction in relation to the development of networks. The participatory organizational design principles that were outlined for facilitation of knowledge exchange are another interesting target of empirical exploration in future research. 


\section{REFERENCES}

Castells, M. The Information Age: Economy, Society and Culture, Volume I: The Rise of the Network Society, Oxford: Blackwell Publishers Ltd., 1996.

Davenport, T. H., De Long, D. W., and Beers, M. C. "Successful Knowledge Management Projects," Sloan Management Review, Winter 1998, pp. 43-57.

Heylighen F. "Principles of Systems and Cybernetics: An evolutionary perspective," in Cybernetics and Systems '92, R. Trappl (ed.), Singapore: World Science, 1992.

Jayaratna, N. Understanding and Evaluating Methodologies: NIMSAD, a Systemic Framework, New York: McGraw-Hill, 1994.

Kotter, J. P. The General Managers, New York: The Free Press, 1982.

Lundgren, A., and Snehota, I. "Ekonomisk organisation som nätverk," in Organisationsteori på svenska, B. Czarniawska (ed.), Malmö, Sweden: Liber (in Swedish), 1998.

Maturana, H., and Varela, F. "Autopoiesis and Cognition: The Realization of the Living" Boston Studies in the Philosophy of Science (Volume 42), Boston: D. Reidel Publishing Co., 1980.

Maxfield, R. R. "Complexity and Organization Management" in Complexity, Global Politics, and National Security, D. S. Alberts and T. J. Czerwinski (eds.), Washington DC: National Defense University, 1997.

Nonaka, I., and Takeuchi, H. The Knowledge Creating Company, New York: Oxford University Press, 1995.

Polanyi, M. Personal Knowledge, London: Routledge and Kegan Paul Ltd., 1958.

Schein, E. H. "Three Cultures of Management: The Key to Organizational Learning," Sloan Management Review, Fall 1996.

Skyrme, D., and Amidon, D. Creating the Knowledge-based Business, London: Business Intelligence Ltd., 1997.

Sterner, H. Knowledge Management Methodologies: Contributions from Systems Thinking, Decision Making and Organizational Learning, Licentiate Thesis, Department of Computer and Systems Sciences, Stockholm University/ Royal Institute of Technology, Sweden. June, 2000.

Swan, J., Scarbrough, H., and Preston, J. "Knowledge Management: The Next Fad to Forget People?" in Proceedings of the Seventh Annual European Conference on Information (ECIS'99), J. Pries-Heje, C. Ciborra, K. Kautz, J. Valor, D. Avison, and C. Heje (eds.), Copenhagen, Denmark: Copenhagen Business School, 1999, pp. 668-678.

Smircich, L., and Morgan, G. "Leadership: The Management of Meaning," The Journal of Applied Behavioral Science (18:3), 1982, pp. 257-273.

Vickers, G. The Art of Judgement, London: Chapman \& Hall, 1965.

Weick, K. E. The Social Psychology of Organizing ( $2^{\text {nd }}$ Edition), New York: Random House, 1979.

\section{About the Author}

Håkan Sterner is a lecturer in information science in the School of Management and Economics at Växjö University, and conducts Ph.D. studies in the Department of Computer and Systems Sciences at Stockholm University. His research focuses on knowledge management, systems thinking, and business intelligence. Håkan can be reached by e-mail at hakan.sterner@ehv.vxu.se. 